\title{
Performance assessment between a ground coupled and air source heat pump used for domestic hot water preparation
}

\author{
Calin Sebarchievici ${ }^{1}$ \\ ${ }^{1}$ University Politehnica of Timisoara, Civil Engineering and Building Services Engineering Department, Timisoara, Romania
}

\begin{abstract}
A ground-coupled heat pump system (GCHP) and an air source heat pump (ASHP) driven by photovoltaic panels are used to provide domestic hot preparation for a NZEB house. The experimental measurements are used to test both the heat pump models in the same conditions of water temperature and volume of domestic hot water. A comparative analysis of the two heat pumps for domestic hot water preparation is performed. In addition, using the software TRNSYS (Transient Systems Simulation), two numerical simulation models of thermal and electrical energy consumption in DHW mode are developed. Finally, the simulations obtained using TRNSYS software are analysed and compared to the experimental data.
\end{abstract}

\section{Introduction}

Buildings are considered one of the largest energy consuming sectors, according to the International Energy Agency (IEA) the average energy consumed by buildings represents $32 \%$ of worldwide energy consumption.

European Union (EU) reveals that buildings are the greatest energy consumer, using approximately $40 \%$ of the total energy demand, followed by industry with $30 \%$ and transportation with approximatively $30 \%$ from total energy demand [1].

Studies have shown that buildings offer the greatest and most cost-effective potential for energy savings reducing also greenhouse gas (GHG) emissions. Some actions are being performed to reduce energy consumption and to protect the environment (e.g., the use of renewable energies for new or retrofitted buildings and passive energy buildings). EU member states must stimulate the transformation of existing buildings undergoing renovation into nearly zero-energy buildings (nZEBs). Conversion of heating and cooling systems based to ground-source heat pumps and air-to-water heat pumps (HPs) is a well-proven measure to approach nZEB requirements. [2]

To realise the ambitious goals for reducing the consumption of fossil fuel as primary energy and the related carbon dioxide (CO2) emissions, and to reach the targets of the Kyoto Protocol, improved energy efficiency and the use of renewable energy in the existing building stock must be addressed in the near future [3].

\section{The heat pump systems}

\subsection{Ground coupled heat pump}

The ground coupled heat pump used in the experiments is composed by a WPC 5 Cool Type model capable to generate heating, cooling and domestic hot water. In our study the heat pump was used only for domestic hot water preparation. Bellow there are the three measurement that were made at different temperature values of the hot water.

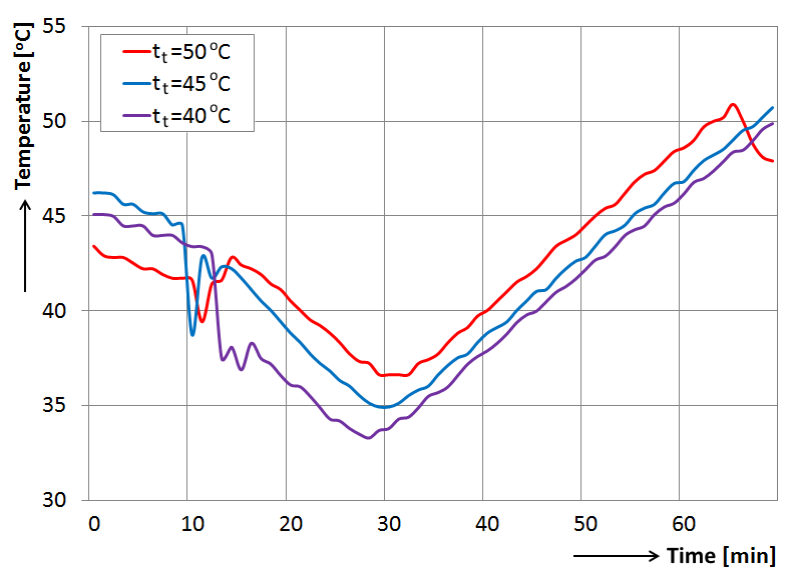

Fig. 1. Temperature of heating agent $\left(\mathrm{t}_{\mathrm{t}}\right)$ for three different hot water temperatures

\subsection{Air source heat pump}

The air source heat pump used in the experiments is composed by a WWK 300 SOL model capable to

\footnotetext{
* Corresponding author: calin.sebarchievici@upt.ro
} 
generate only domestic hot water. Bellow is shown the temperature for hot water three measurement that were made at different temperature values of the hot water.

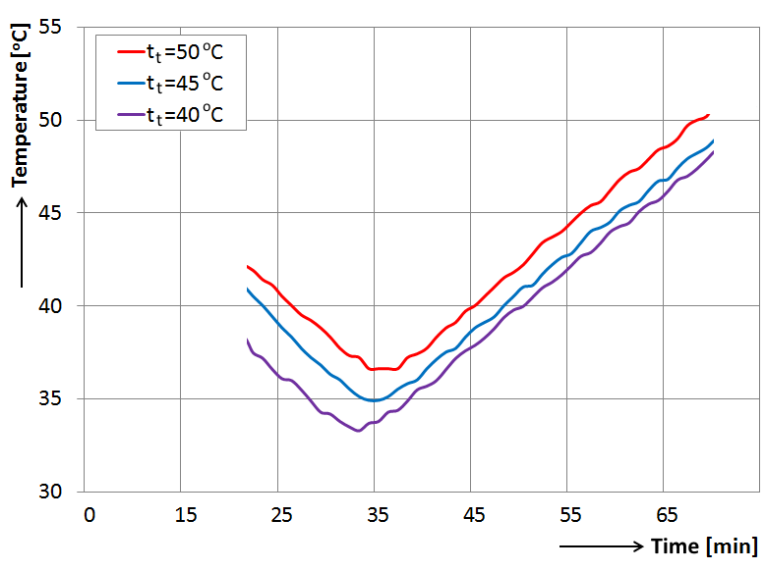

Fig. 2. Temperature of heating agent $\left(\mathrm{t}_{\mathrm{t}}\right)$ for three different hot water temperatures

\section{TRNSYS simulation models}

In the figure 3 is described the simulation model for the ground coupled heat pump.

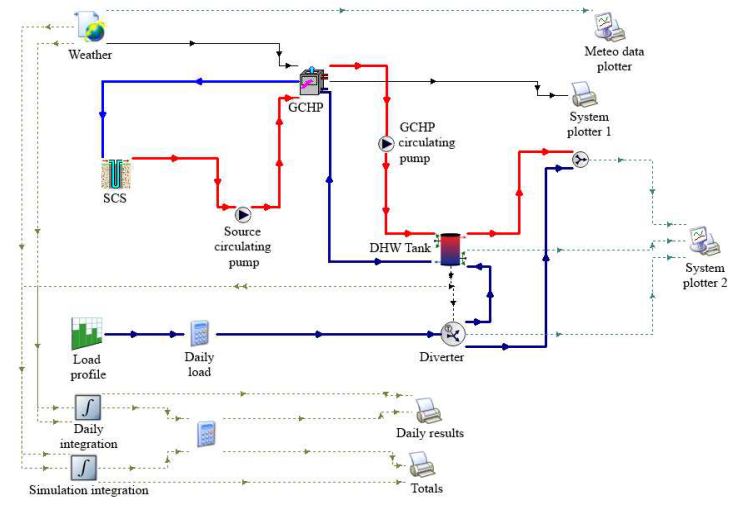

Fig. 3. Ground Coupled Heat Pump simulation in TRNSYS.

In the figure 4 is described the simulation model for the air source heat pump.

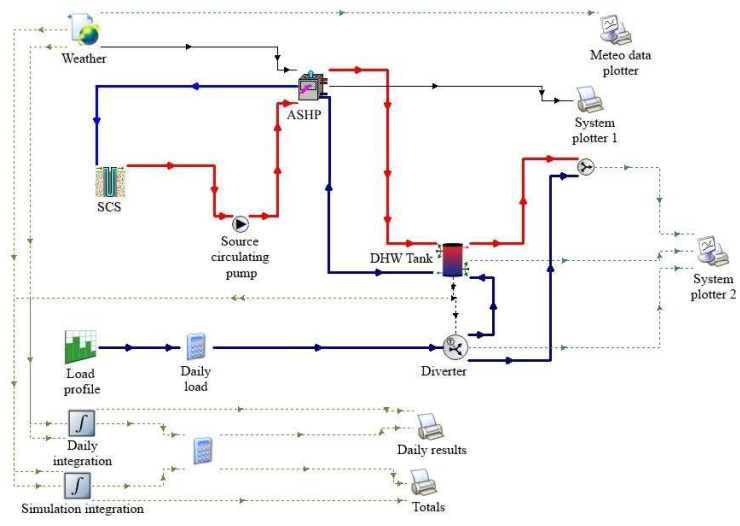

Fig. 4. Air Source Heat Pump simulation in TRNSYS.

\section{Comparison between measurements and simulations}

As it can be seen in the graphics the difference between the two types of heat pumps is the time, showing the the different capacity of the sources: air and the ground.

This also will be shown in the table of consumption measurements, with higher consumption of the air source heat pump and lower consumption of the ground coupled heat pump.

Table 1. Comparison between experimental data and simulation data for ground coupled heat pump

Table 1A - Measurements

\begin{tabular}{|c|c|c|c|c|c|c|}
\hline $\begin{array}{c}\text { Nr. } \\
\text { crt. }\end{array}$ & $\begin{array}{c}t_{t m} \\
{\left[{ }^{\circ} \mathrm{C}\right]}\end{array}$ & $\begin{array}{c}t_{s m} \\
{\left[{ }^{\circ} \mathrm{C}\right]}\end{array}$ & $\begin{array}{c}V_{\text {acm }} \\
{\left[\mathrm{m}^{3}\right]}\end{array}$ & $\begin{array}{c}E_{t \text { meas }} \\
{[\mathrm{kWh}]}\end{array}$ & $\begin{array}{c}E_{\text {el meas }} \\
{[\mathrm{kWh}]}\end{array}$ & $\mathrm{COP}_{\text {meas }}$ \\
\hline \hline 1. & 43.35 & 9.42 & & 4.59 & 1.93 & 2.37 \\
\cline { 1 - 4 } & 41.97 & 7.74 & \multirow{2}{*}{0.150} & 4.48 & 1.88 & 2.38 \\
\cline { 1 - 4 } \cline { 5 - 7 } & 40.68 & 7.37 & & 4.43 & 1.75 & 2.53 \\
\hline
\end{tabular}

Table 1B - Simulations
\begin{tabular}{|c|c|c|c|c|c|c|}
\hline $\begin{array}{c}\text { Nr. } \\
\text { crt. }\end{array}$ & $\begin{array}{c}t_{t m} \\
{\left[{ }^{\circ} \mathrm{C}\right]}\end{array}$ & $\begin{array}{c}t_{s m} \\
{\left[{ }^{\circ} \mathrm{C}\right]}\end{array}$ & $\begin{array}{c}V_{\text {acm }} \\
{\left[\mathrm{m}^{3}\right]}\end{array}$ & $\begin{array}{c}E_{t \text { sim }} \\
{[\mathrm{kWh}]}\end{array}$ & $\begin{array}{c}E_{\text {el siim }} \\
{[\mathrm{kWh}]}\end{array}$ & $\mathrm{COP}_{\text {sim }}$ \\
\hline \hline 1. & 43.35 & 9.42 & & 4.65 & 1.91 & 2.43 \\
\hline 2. & 41.97 & 7.74 & \multirow{2}{*}{0.150} & 4.55 & 1.85 & 2.45 \\
\cline { 1 - 4 } \cline { 5 - 7 } & 40.68 & 7.37 & & 4.48 & 1.71 & 2.61 \\
\hline
\end{tabular}

Table 2. Comparison between experimental data and simulation data for air source heat pump

Table 2A - Measurements

Table 2A - Measurements
\begin{tabular}{|c|c|c|c|c|c|c|}
\hline $\begin{array}{c}\text { Nr. } \\
\text { crt. }\end{array}$ & $\begin{array}{c}t_{\text {tm }} \\
{\left[{ }^{\circ} \mathrm{C}\right]}\end{array}$ & $\begin{array}{c}t_{s m} \\
{\left[{ }^{\circ} \mathrm{C}\right]}\end{array}$ & $\begin{array}{c}V_{\text {acm }} \\
{\left[\mathrm{m}^{3}\right]}\end{array}$ & $\begin{array}{c}E_{t \text { meas }} \\
{[\mathrm{kWh}]}\end{array}$ & $\begin{array}{c}E_{\text {el meas }} \\
{[\mathrm{kWh}]}\end{array}$ & $\mathrm{COP}_{\text {meas }}$ \\
\hline \hline 1. & 43.85 & 9.12 & & 4.89 & 2.71 & 1.80 \\
\hline 2. & 42.22 & 7.94 & \multirow{3}{*}{0.150} & 4.58 & 2.52 & 1.81 \\
\cline { 1 - 4 } \cline { 5 - 7 } & 41.11 & 7.88 & & 4.52 & 2.31 & 1.95 \\
\hline
\end{tabular}

Table 2B - Simulations
\begin{tabular}{|c|c|c|c|c|c|c|}
\hline $\begin{array}{c}\text { Nr. } \\
\text { crt. }\end{array}$ & $\begin{array}{c}t_{t m} \\
{\left[{ }^{\circ} \mathrm{C}\right]}\end{array}$ & $\begin{array}{c}t_{s m} \\
{\left[{ }^{\circ} \mathrm{C}\right]}\end{array}$ & $\begin{array}{c}V_{\text {acm }} \\
{\left[\mathrm{m}^{3}\right]}\end{array}$ & $\begin{array}{c}E_{t \text { sim }} \\
{[\mathrm{kWh}]}\end{array}$ & $\begin{array}{c}E_{\text {el sim }} \\
{[\mathrm{kWh}]}\end{array}$ & $\mathrm{COP}_{\text {sim }}$ \\
\hline \hline 1. & 43.85 & 9.12 & & 4.95 & 2.62 & 1.88 \\
\hline 2. & 42.22 & 7.94 & \multirow{3}{*}{0.150} & 4.62 & 2.44 & 1.89 \\
\hline 3. & 41.11 & 7.88 & & 4.57 & 2.24 & 2.04 \\
\hline
\end{tabular}

\section{References}

1. Anisimova, N. The capability to reduce primary energy demand in EU housing. Energy Build. 2011, 43, 2747-2751.

2. Sarbu, I, Sebarchievici C. Performance Evaluation of Radiator and Radiant Floor Heating Systems for an Office Room Connected to a Ground-Coupled Heat Pump, Energies 2016, 9, 228

3. Bendea, G.V.; Prada, M.F.; Bendea, C.; Secui, C. Ground-coupled heat pump systems - A key for a suistainable development of heating and cooling buildings. In recent Advances in Environmental Science, Proceedings of the 9th International Conference on Energy, Environment, Ecosystems and Sustainable Development, Lemesos, Cyprus, 21-23 March 2013; pp. 133-138 